\title{
Synthesis, surface tension, optical and dielectric properties of bismuth oxide thin film
}

\author{
FAtMa Meydanerí TeZel ${ }^{1, *}$, İ. Afşin KARIPER ${ }^{2}$ \\ ${ }^{1}$ Department of Metallurgy and Materials Engineering, Faculty of Engineering, Karabük University, 78050, Karabük, Turkey \\ ${ }^{2}$ Department of Science Education, Education Faculty, Erciyes University, 38039, Kayseri, Turkey
}

Bismuth oxide thin film was deposited by chemical bath deposition (CBD) technique onto a glass substrate. The grain size $(\mathrm{D})$, dislocation density $(\delta)$ and number of crystallites per unit area $(\mathrm{N})$, i.e. structural properties of the thin film were determined as $16 \mathrm{~nm}, 39.06 \times 10^{-4}$ line $/ \mathrm{nm}^{2}, 31.25 \times 10^{-3} 1 / \mathrm{nm}^{2}$, respectively. Optical transmittance properties of the thin film were investigated by using a UV-Vis spectrophotometer. The optical band gap $\left(\mathrm{E}_{\mathrm{g}}\right)$ for direct transitions, optical transmission ( $\mathrm{T} \%)$, reflectivity $(\mathrm{R} \%)$, absorption, refractive index $\left(\mathrm{n}_{\mathrm{r}}\right)$, extinction coefficient $(\mathrm{k})$, dielectric constant $(\epsilon)$ of the thin film were found to be $3.77 \mathrm{eV}, 25.23 \%, 32.25 \%, 0.59,3.62,0.04$ and 2.80, respectively. The thickness of the film was measured by AFM, and was found to be $128 \mathrm{~nm}$. Contact angles of various liquids on the oxide thin film were determined by Zisman method, and surface tension was calculated to be $31.95 \mathrm{mN} / \mathrm{m}$.

Keywords: CBD technique; crystal growth; Zisman method; optical properties; surface tension

(C) Wroclaw University of Science and Technology.

\section{Introduction}

Significant applications of bismuth oxides in the fields such as microelectronics [1], sensor technology [2], optical coatings [3], transparent ceramic glass manufacturing [4] have been discovered during the last years. The material is characterized by a large energy band-gap, high photoconductivity, high refractive index, dielectric permittivity and photoluminescence. During the growth of crystallites with different geometric shapes, various phases occur. Until now, five polymorphic forms of bismuth oxides were obtained: two stable polymorphs, namely $\alpha$ and $\delta$ phases $\left(\alpha-\mathrm{Bi}_{2} \mathrm{O}_{3}\right.$ is monoclinic, $\delta-\mathrm{Bi}_{2} \mathrm{O}_{3}$ is face-centered cubic), and three metastable phases, i.e. $\beta, \gamma$ and $\omega\left(\beta-\mathrm{Bi}_{2} \mathrm{O}_{3}\right.$ is tetragonal, $\gamma-\mathrm{Bi}_{2} \mathrm{O}_{3}$ is body-centered cubic, $\omega$ $\mathrm{Bi}_{2} \mathrm{O}_{3}$ is triclinic) $[5-13,35]$. For nanometric thicknesses, $\mathrm{BiO}$ is predominant phase, while in case of micronic films, $\alpha-\mathrm{Bi}_{2} \mathrm{O}_{3}$ and $\mathrm{Bi}_{2} \mathrm{O}_{3}$ are the main phase components [11].

Thin films of bismuth oxides have been obtained using such methods as electrodeposition,

*E-mail: meydaneri@yahoo.com thermal evaporation under vacuum, sol-gel, pulsed laser deposition, etc., and their optical properties, formation of different phases and phase relations have been investigated [14-21]. However, none of them is as simple and economical as the method described in this study. The optical properties and surface tension of nanoparticles are very sensitive to the method of preparation, crystallite size and doping. However, the CBD (chemical bath deposition) method is one of the simplest chemical methods in which the nanoparticles can be prepared quickly with very good crystallinity.

In the present paper, we have attempted to produce thin films of bismuth oxides using a modified chemical bath deposition method from those described in the literature. $\mathrm{Bi}_{2} \mathrm{O}_{2.75}$ synthesized by this method has been scarcely reported. Then, we examined the optical, structural and surface tension properties of the films.

\section{Experimental}

\subsection{Synthesis and characterization of thin film}

Glass (microscope slides) was used as a substrate material in the experiments. Microscope 
slides were heated in a nitric acid solution at $100^{\circ} \mathrm{C}$ for 1 hour. All used chemicals were of analytical reagent grade. $100 \mathrm{~mL}$ of $0.1 \mathrm{M}$ bismuth (III) nitrate pentahydrate solution was prepared in a beaker. $10 \mathrm{~mL}$ of the solution was transferred into an empty beaker and $1000 \mu \mathrm{L}$ hydrogen peroxide was added to the solution. The distilled water was added until the final volume of chemical bath achieved $40 \mathrm{~mL}$. The pre-washed and cleaned substrates (microscope slides) were immersed into the prepared solution. Finally, the chemical bath with the substrates was kept in a drying oven at $40{ }^{\circ} \mathrm{C}$ for $1 \mathrm{~h}$. At the end of this period, the surfaces of the microscope slides were covered with a white film, and the microscope slides were removed from the chemical bath.

The crystalline structure of bismuth oxides was confirmed by X-ray diffraction (XRD) with a $\mathrm{CuK} \alpha_{1}$ radiation source (Rigaku RadB model, $\lambda=1.5406 \AA$ ) over the $2 \theta$ range $10^{\circ}<2 \theta<90^{\circ}$ at a speed of $3^{\circ} \cdot \mathrm{min}^{-1}$ with a step size of $0.02^{\circ}$. The surface properties of the film were investigated by using field emission scanning electron microscope (FESEM) Carl Zeiss Ultra Plus. The transmittance and absorbance measurements of the film were recorded by a PerkinElmer UV-Vis Lambda $2 \mathrm{~S}$ spectrophotometer (double-beam) at room temperature by placing an uncoated identical glass substrate under the reference beam in the wavelength range of $200 \mathrm{~nm}$ to $1100 \mathrm{~nm}$. The thickness of the film was measured with a Veeco MultiMode Atomic Force Microscope (Nanoscope 3D controller). The surface tension was measured with a contact angle meter KSV CAM200, KSV Instruments, at room temperature, room conditions, and in a controlled air flow.

\section{Results and discussion}

\subsection{Structural properties}

The color of thin film of bismuth oxide is white. The crystal structure and orientation of crystallization were determined by XRD measurement (Fig. 1). Only one peak is observed at the diffraction angle of $31.825^{\circ}$ for the $\mathrm{Bi}_{2} \mathrm{O}_{2.75}$ thin film. The diffraction pattern shows that the $\mathrm{Bi}_{2} \mathrm{O}_{2.75}$ thin film is a body-centered tetragonal structure $(\mathrm{a}=\mathrm{b}=$ $3.85 \AA$; and $c=12.25 \AA$ ), with the main crystal orientation along (llll $\left.\begin{array}{lll}1 & 0 & 3\end{array}\right)$ plane. The observed (d) value of the Bragg's interplanar spacing is found to be $2.80956 \AA$. The crystal orientation, the diffraction angle and Bragg's interplanar spacing reported in the literature are (1 03 3 $), 32.825^{\circ}$ and $2.80100 \AA$ (ASTM, PDF Card No. 27-0049), respectively.

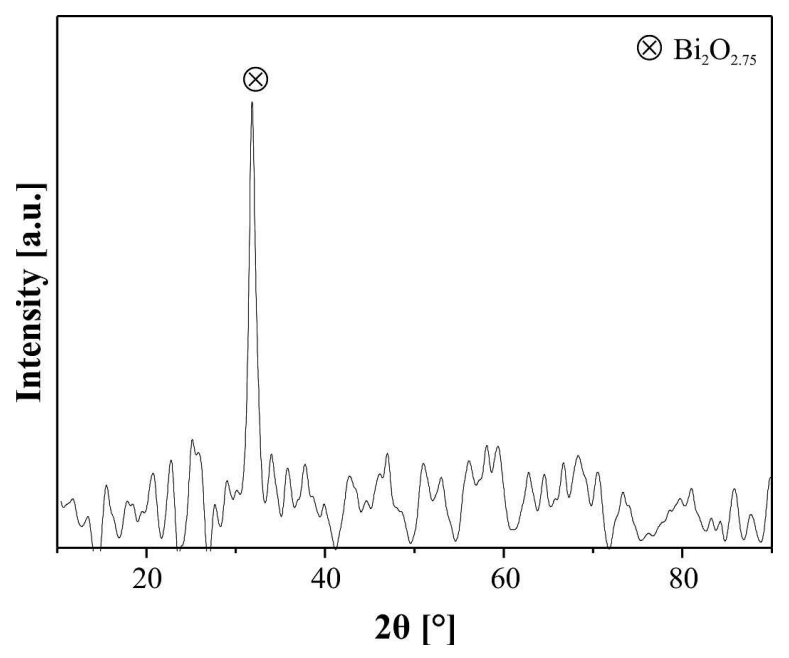

Fig. 1. XRD pattern of $\mathrm{Bi}_{2} \mathrm{O}_{2.75}$ thin film.

The average grain size (D) of the nanocrystalline $\mathrm{Bi}_{2} \mathrm{O}_{2.75}$ was calculated by XPowder computer program with respect to high intensity peak of XRD patterns using Debye Scherrer's formula [22-24]:

$$
D=\frac{K \lambda}{\beta \cos \theta}
$$

where $\mathrm{D}$ is the grain size, $\mathrm{K}$ is a constant which is taken as $0.9, \lambda$ is the $\mathrm{X}$-ray wavelength, $\beta$ is the angular line width at half-maximum intensity in radians and $\theta$ is Bragg angle. Dislocation density $(\delta)$ was calculated using the formula given below:

$$
\delta=\frac{1}{D^{2}}
$$

where $\delta$ is dislocation density which is defined as the length of dislocation lines per unit volume of the crystal. The dislocation density $(\delta)$ gives more information about the amount of defects in the films. 
Higher $\delta$ values indicate lower crystallinity level of the films and indicate the amount of defects in the structure. Films with smaller $\delta$ values indicate better crystallization in the films [22-24]. The higher $\mathrm{N}$ value indicates extensive crystallization. The number of crystallites per unit area $(\mathrm{N})$ is calculated by using the formula:

$$
N=\frac{t}{D^{3}}
$$

where $\mathrm{t}$ is the film thickness. The thickness of the film was measured by AFM, and was found to be $128 \mathrm{~nm}$. The grain size (D), dislocation density $(\delta)$ and number of crystallites per unit area $(\mathrm{N})$, i.e. structural properties of the thin film were obtained to be $16 \mathrm{~nm}, 39.06 \times 10^{-4}$ line $/ \mathrm{nm}^{2}$, $31.25 \times 10^{-3} 1 / \mathrm{nm}^{2}$, respectively.

The surface morphology of thin film was obtained by FESEM at magnification of $5000 \times$ and $10000 \times$. The surface properties directly affect the optical properties of the films. The SEM images of the $\mathrm{Bi}_{2} \mathrm{O}_{2.75}$ thin film are presented in Fig. 2. According to the SEM analysis of the film (Fig. 2), the surface is made up of different-sized spherical structures. The particles are well separated from each other. Surface morphology is homogeneous and dense, cluster sizes are very small, the clusters are packed tightly and have strong adherence to the substrate. In the magnified image, the surface looks like as composed of cauliflower clusters.

There are no cracks on the film surface. Good crystallization of the structure is due to the low temperature of reaction, resulting from low reaction rate and the nature of glass substrate which makes that the dislocation density is also very low. Table 1 shows the percentage elemental composition of the $\mathrm{Bi}_{2} \mathrm{O}_{2.75}$ thin film and bare glass.

\subsection{Optical and dielectric properties}

Transmission measurements were performed at room temperature in the range of $200 \mathrm{~nm}$ to $1100 \mathrm{~nm}$ to obtain information on the optical properties of the $\mathrm{Bi}_{2} \mathrm{O}_{2.75}$ thin film deposited on the microscope slides. The transmittance $(T)$ of the thin film can be calculated by using reflectivity $(\mathrm{R})$ and absorbance (A) spectra, from the expression [25]:

$$
T=(1-R)^{2} e^{-A}
$$

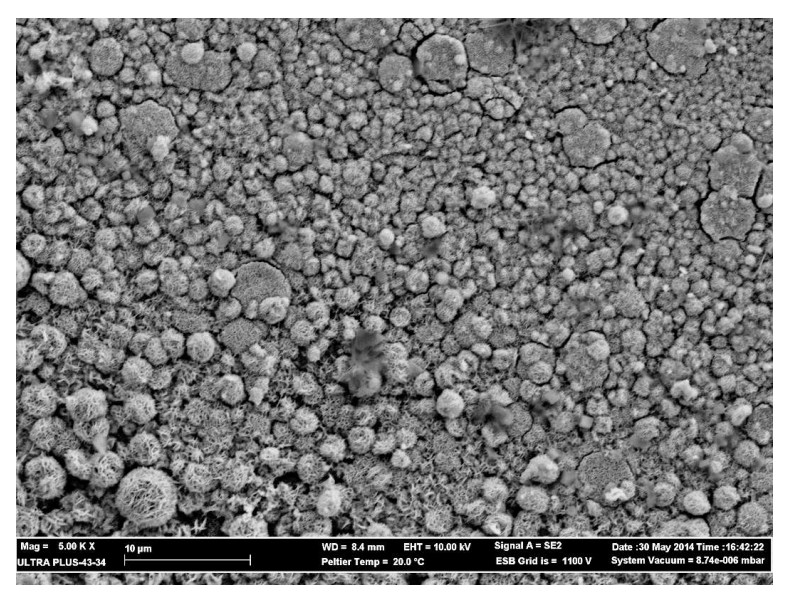

(a)

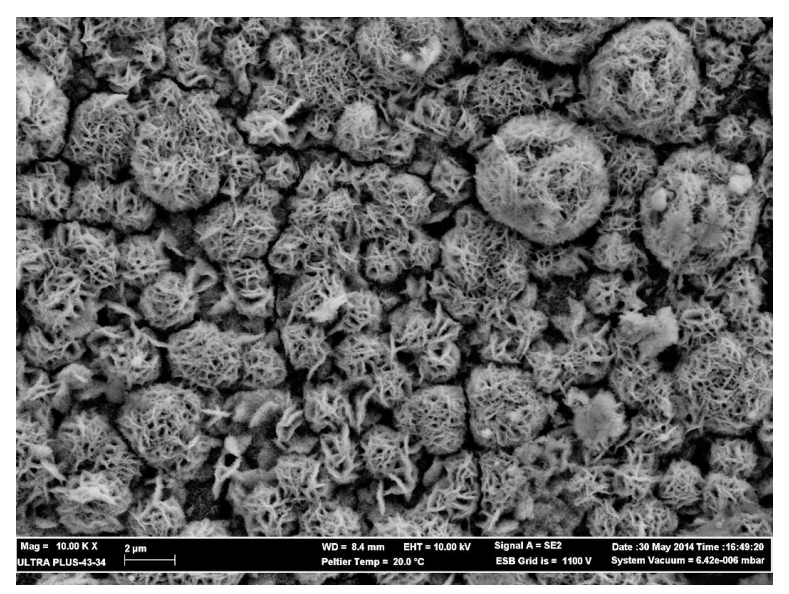

(b)

Fig. 2. The surface morphology (SEM) of $\mathrm{Bi}_{2} \mathrm{O}_{2.75}$ thin film.

Table 1. Percentage elemental composition of the

\begin{tabular}{|c|c|c|}
\hline Element & Bare glass & Bismuth oxide $\left(\mathrm{Bi}_{2} \mathrm{O}_{2.75}\right)$ \\
\hline $\mathrm{Na}$ & 9.02 & 5.14 \\
\hline $\mathrm{Mg}$ & 2.26 & 1.37 \\
\hline $\mathrm{Al}$ & 0.72 & 0.49 \\
\hline $\mathrm{Si}$ & 35.10 & 29.46 \\
\hline K & 0.21 & - \\
\hline $\mathrm{Ca}$ & 5.63 & 5.78 \\
\hline $\mathrm{O}$ & 47.06 & 19.21 \\
\hline $\mathrm{Bi}$ & - & 38.56 \\
\hline
\end{tabular}
$\mathrm{Bi}_{2} \mathrm{O}_{2.75}$ thin film and bare glass.

The optical transmission and the reflectivity were determined to be $25.23 \%$ and $32.25 \%$ in the visible region (at $550 \mathrm{~nm}$ wavelength), 
respectively, and have been presented in Fig. 3. The absorbance change versus the wavelength of $\mathrm{Bi}_{2} \mathrm{O}_{2.75}$ thin film is shown in Fig. 4.
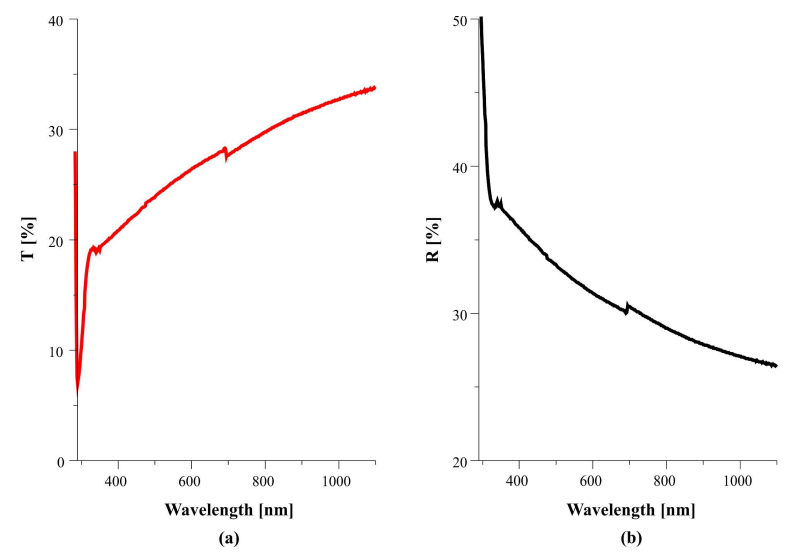

Fig. 3. Transmittance $\mathrm{T}[\%]$ and reflectivity $\mathrm{R}[\%]$ of $\mathrm{Bi}_{2} \mathrm{O}_{2.75}$ thin film versus wavelength.

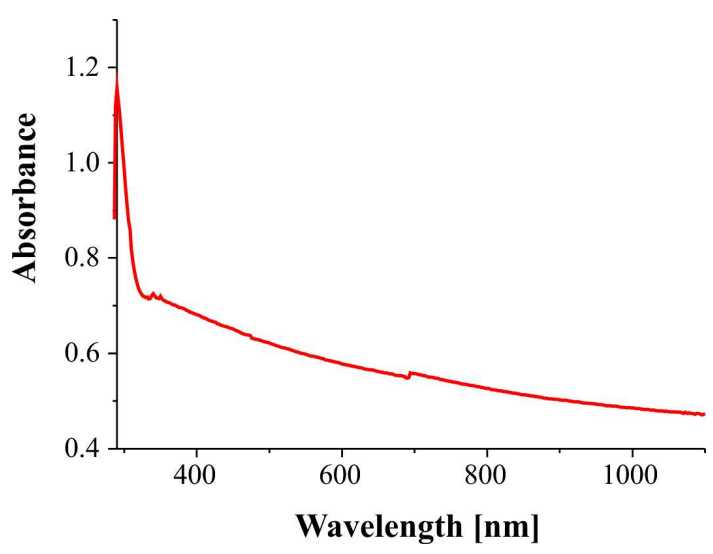

Fig. 4. Absorbance of $\mathrm{Bi}_{2} \mathrm{O}_{2.75}$ thin film versus wavelength.

As seen from Fig. 4, the absorbance is 0.598 in the visible region. The absorption coefficient, $\alpha$ determines how deep light of a particular wavelength can penetrate into a material before it is absorbed. Once absorption coefficient is determined, the value of optical band gap can be found. The value of optical band gap energy has been established from the absorption spectra of the films by using the following formula [26-29]:

$$
(\alpha h v)=A\left(h v-E_{g}\right)^{n}
$$

where $\alpha$ is the absorption coefficient, (hv) is the photon energy, $\mathrm{A}$ is a constant and $\mathrm{n}$ value equals to
1/2 for direct band gap semiconductor. Fig. 5 shows the plot of $(\alpha h v)^{2}$ versus (hv) for the $\mathrm{Bi}_{2} \mathrm{O}_{2.75}$ thin film. The straight-line was extrapolated to the energy axis at $\alpha=0$, to obtain the band gap value of the film which was found to be $3.77 \mathrm{eV}$. The band gaps of nanometric (up to $\sim 60 \mathrm{~nm}$ ) and the submicronic films $(\mathrm{d} \sim 0.15 \mu \mathrm{m})$ were determined by Leontie et al. [8] as $2.5 \mathrm{eV}$ and $3.3 \mathrm{eV}$, respectively. They found that the grain size is inversely proportional to the optical band gap and that the film thickness affects the optical band gap.

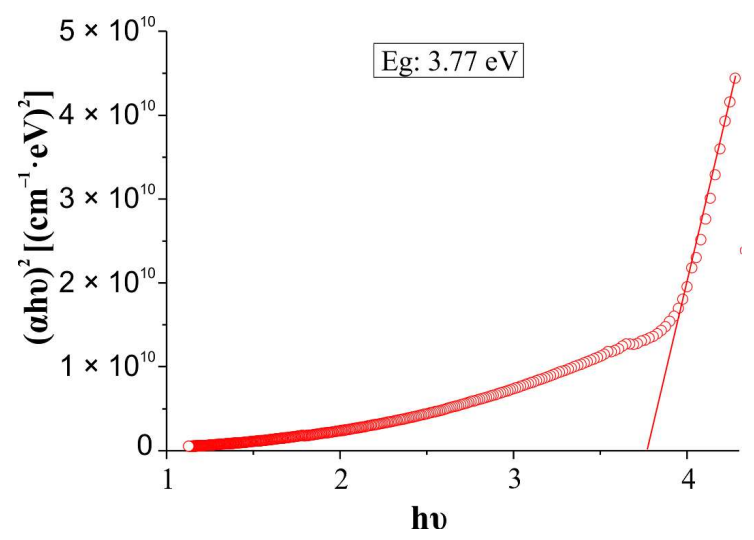

Fig. 5. Plot of $(\alpha h v)^{2}$ versus $h v$ for $\mathrm{Bi}_{2} \mathrm{O}_{2.75}$ thin film.

Quantum size effect on the optical band gap was discussed in the literature [26-30]. The effect of structure on the optical band gap results from the fact that the number of grains per unit cell and the number of spaces per unit cell affect the density of the unit cell (in the present work molecular weight $=461.96 \mathrm{~g} / \mathrm{mol}$, density $=8.449 \mathrm{~g} / \mathrm{cm}^{3}$ ). Bismuth in $\mathrm{Bi}_{2} \mathrm{O}_{2.75}$ and $\mathrm{Bi}_{2} \mathrm{O}_{3}$ generally tends to occupy octahedral positions, since the additional oxygen required for octahedral coordination of $\mathrm{Bi}$ is provided by the oxygen atoms in the host matrix through non-bonding coordination, and so structures based on heavy metal oxide occur [31].

Refractive index $\left(\mathrm{n}_{\mathrm{r}}\right)$ and extinction coefficient (k) for the thin films are given by following formula [25]:

$$
\begin{gathered}
n_{r}=\frac{1+R}{1-R}+\sqrt{\frac{4 R}{(1-R)^{2}}-k^{2}} \\
k=\frac{\alpha \lambda}{4 \pi}
\end{gathered}
$$


The refractive index and extinction coefficient for $\mathrm{Bi}_{2} \mathrm{O}_{2.75}$ thin film are presented in Fig. 6 .

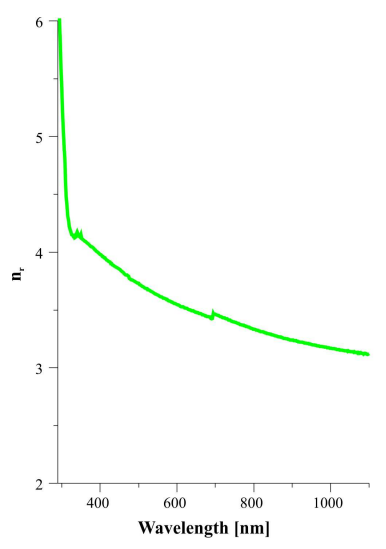

(a)

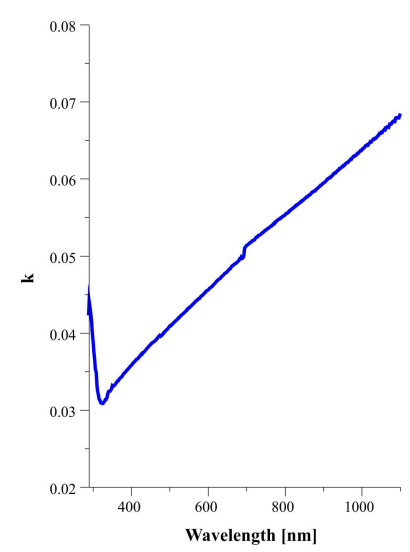

(b)
Fig. 6. Refractive index $\left(\mathrm{n}_{\mathrm{r}}\right)$ and extinction coefficient (k) of $\mathrm{Bi}_{2} \mathrm{O}_{2.75}$ thin film versus wavelength.

The refractive index graph has a shape similar to reflection curve. The film thickness affects the refractive index and extinction coefficient. The refractive index and extinction coefficient values were found to be 3.62 and 0.04 at $550 \mathrm{~nm}$ wavelength. This result is consistent with the literature [32].

The optical constants are parameters which characterize how a material responds to excitation by an electromagnetic radiation at a given frequency. These optical constants can be expressed as a complex dielectric function by the following formula:

$$
\varepsilon=\varepsilon_{1}+i \varepsilon_{2}
$$

or as a complex refractive index by the following formulae:

$$
\begin{gathered}
n=n+i k \\
\varepsilon_{1}=n^{2}-k^{2} \\
\varepsilon_{2}=2 n k
\end{gathered}
$$

The real part or refractive index $\left(\mathrm{n}_{\mathrm{r}}\right)$ defines the phase velocity of light in a material. The imaginary part or extinction coefficient $(\mathrm{k})$ determines how fast the amplitude of the wave decreases. Thus, the optical constants represent the optical properties of a material in terms of how an electromagnetic wave propagates in this material. The dielectric constants, $\epsilon_{1}$ and $\epsilon_{2}$ versus the wavelength for $\mathrm{Bi}_{2} \mathrm{O}_{2.75}$ thin film are shown in Fig. 7, and their calculated values are 2.80 and 0.14 , respectively.

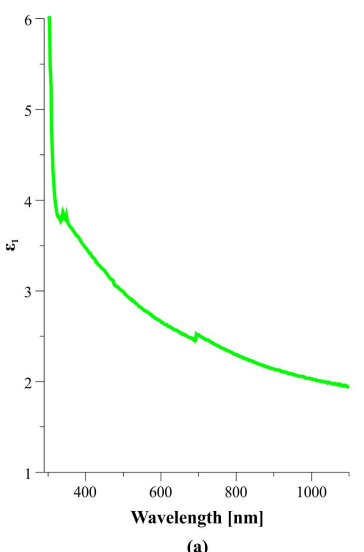

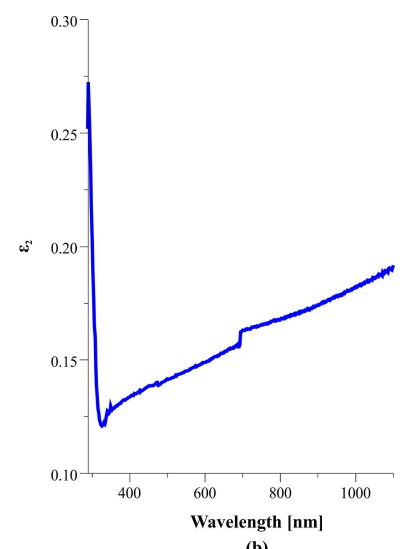

(b)
Fig. 7. Variation of the real and imaginary parts of dielectric constant for the $\mathrm{Bi}_{2} \mathrm{O}_{2.75}$ thin film versus wavelength.

High-index materials are used to make filters and mirrors with special reflection employed in lasers. This kind of structures based on heavy metal oxides have wide applications in the field of glass ceramics, layers for optical and electronic devices, thermal and mechanical sensors, reflecting windows, etc. [33].

\subsection{Surface tension}

Pure glycerin, iodometane, water and ethylene glycol of analytical grade were used for the contact angle measurements. The surface tension of test liquids was determined by using pendant drop method (KSV CAM200, KSV Instruments, Finland). The values of surface tension of these liquids are presented in Table 2. The surface tension tests were performed at room temperature. The important issue is to select appropriate liquid in order to employ Zisman method. Zisman found that $\cos \theta$ is a function $\gamma_{1}$ :

$$
\cos \theta=a-b \gamma_{1}=1-\beta\left(\gamma_{1}-\gamma_{c r}\right)
$$


where $\gamma_{\mathrm{cr}}$ is critical surface tension of a solid which is a characteristic feature of any solid. Any liquid with $\gamma_{1}<\gamma_{\mathrm{cr}}$ will wet the surface. Critical surface tension is close to the solid surface tension and this method can be applied in thin film with $\gamma_{\mathrm{s}} \sim \gamma_{\mathrm{cr}}$ [34]. Critical surface energies of a film can be assigned to $\cos \theta$ by using the curves obtained from the plot of liquid surface tension, by simulation method or from the $\mathrm{y}=\mathrm{Ax}+\mathrm{B}$ curve obtained from those plots. In this equation, $\mathrm{x}$ value for $\mathrm{y}=1$ can be calculated easily.

Table 2. Surface tension of test liquids used in the experiments.

\begin{tabular}{lc}
\hline \multicolumn{1}{c}{ Liquid } & $\gamma[\mathrm{mN} / \mathrm{m}]$ \\
\hline \hline Water & 72.8 \\
Glycerin & 64 \\
Ethylene glycol & 48 \\
Iodometane & 35.27 \\
\hline
\end{tabular}

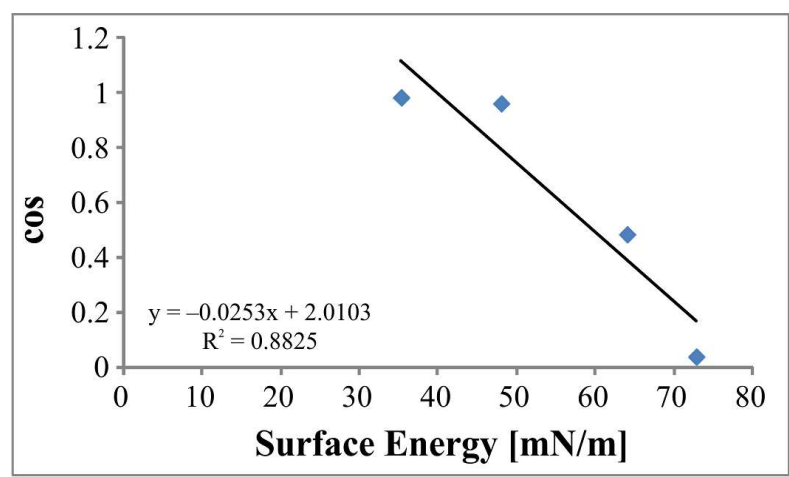

Fig. 8. Contact angel plot of the test liquids on the $\mathrm{Bi}_{2} \mathrm{O}_{2.75}$ thin film.

Table 3. Contact angles of test liquids on $\mathrm{Bi}_{2} \mathrm{O}_{2.75}$ thin film.

\begin{tabular}{|c|c|c|c|}
\hline Wate & Slyce & ene & ometane \\
\hline 78 & 63 & 52 & 9 \\
\hline
\end{tabular}

Contact angle and surface tension are presented in Fig. 8; additionally, the contact angles of the test liquids on $\mathrm{Bi}_{2} \mathrm{O}_{2.75}$ thin film are presented in Table 3. Surface tension was found to be $31.95 \mathrm{mN} / \mathrm{m}$.

\section{Conclusions}

In this study, $\mathrm{Bi}_{2} \mathrm{O}_{2.75}$ thin films have been produced for the first time on microscope slides by chemical bath deposition method. Crystal structure parameters, average grain size (D), dislocation density $(\delta)$, number of crystallites per unit area $(\mathrm{N})$, thickness of the film and surface morphology of the nanocrystalline $\mathrm{Bi}_{2} \mathrm{O}_{2.75}$ thin film were investigated. The optical band gap $\left(\mathrm{E}_{g}\right)$ for direct transitions, optical transmission (T \%), reflectivity ( $\mathrm{R} \%)$, absorption coefficient, refractive index $\left(\mathrm{n}_{\mathrm{r}}\right)$, extinction coefficient $(\mathrm{k})$, dielectric constant $(\epsilon)$ of the thin films were investigated. According to the results, the low rate of reaction, temperature and the structure of substrate affected structural and optical properties of the film. Additionally, the surface tension of $\mathrm{Bi}_{2} \mathrm{O}_{2.75}$ thin film was studied for the first time. The produced thin film has hydrophobic properties, and its surface tension was found to be $31.95 \mathrm{mN} / \mathrm{m}$.

\section{Acknowledgements}

This work was supported by the Karabük University Scientific Research Project Unit under Contract No. KBÜ-BAP13/1-YL-033 and the Erciyes University Technopark. The authors would like to thank the Karabük University Scientific Research Project Unit for their financial support.

\section{References}

[1] Bandoli G., Barecca D., Brescacin E., Rizzi G.A., Tondello E., Chem. Vapor Depos., 2 (1996), 238.

[2] Hyodo T., Kanazawa E., Takao Y., Shimizu Y., EgASHIRA M., Electrochemistry, 68 (2000), 24.

[3] Schuisky M., HÄRsta A., Chem. Vapor Depos., 2 (1996), 235.

[4] Pan A., Ghosh A., J. Non-Cryst. Solids, 271 (2000), 157.

[5] Gobrecht H., Seeck S., Bergt H.-E., Märtens A., Kossmann K., Phys. Status Solidi, 33 (1969), 599.

[6] Dolocan V., Iova F., Phys. Status Solidi A, 64 (1981), 755.

[7] Dolocan V., Appl. Phys. A-Mater., 16 (1978), 405.

[8] Leontie L., Caraman M., Delibaş M., Rusu G.I., Mater. Res. Bull., 36 (2001), 1629.

[9] Leontie L., Caraman M., Rusu G.I., J. Optoelectron. Adv. M., 2 (2000), 385.

[10] Condurache-Bota S., Rusu G.I., TुigăU N., Draşovean R., GHeOrghieş C., Rev. Roum. Chim., 54 (2009), 205. 
[11] Leontie L., Caraman M., Alexe M., HarNAGEA C., Surf. Sci., 507 - 510 (2002), 480.

[12] Harwig H.A., Z. Anorg. Allg. Chem., 444 (1978), 151.

[13] ShuK P., Wiemhöfer H.-D., Guth U., GöPEL W., GreEnblatt M., Solid State Ionics, 89 (1996), 179.

[14] RAID I.A., e-JSSNT, 4 (2006), 563.

[15] Huang C.C., Wen T.Y., Fung K.Z., Mater. Res. Bull., 41 (2006), 110.

[16] Kumari L., Lin J.H., Ma Y.R., J. Phys. D Appl. Phys., 41 (2008), 025405.

[17] Gotic M., Popovic S., Music S., Mater. Lett., 61 (2007), 709.

[18] Patil M.M., Deshpande V.V., Dhange S.R., RAVI V., Mater. Lett., 59 (2005), 2523.

[19] Fan H.T., Pan S.S., Tens X.M., Ye C., Li G.H., ZHANG L.D., Thin Solid Films, 513 (2006), 142.

[20] Leontie L., Caraman M., Visinoiu A., Rusu G.I., Thin Solid Films, 473 (2005), 230.

[21] Kang S.W., Rhee S.W., Thin Solid Films, 468 (2004), 79.

[22] Cullity B.D., Elements of X-ray Diffraction, $2^{\text {nd }}$ Edition, Addison-Wessley, California, 1978, p. 102.

[23] Motт N.F., DaVIs E.A., Electronic Processes in NonCrystalline Materials, Clarendon Press, Oxford, 1979, p. 273.

[24] Mamazza R., Morel D.L., Ferekides C.S., Thin Solid Films, 484 (2005), 26.
[25] Pejova B., Grozdanov I., Tanusevski A., Mater. Chem. Phys., 83 (2004), 245.

[26] Akaltun Y., Yildirim M.A., ATEŞ A., YILDIRIM M., Opt. Commun., 284 (2011), 2307.

[27] Mahalingam T., John V.S., Rajendran S., SEBASTIAN P.J., Semicond. Sci. Tech., 17 (2002), 465.

[28] Thanikaikarasan S., Mahalingam T., Raja M., KIM T., KIM Y.D., J. Mater. Sci. Mater. El., 20 (2009), 727.

[29] Yildirim M.A., Ateş A., Opt. Commun., 283 (2010), 1370.

[30] Shinde V.R., Lokhande C.D., Mane R.S., SungHwan H., Appl. Surf. Sci., 245 (2005), 407.

[31] Krogh-Moe J., Phys. Chem. Glasses-B, 6 (1965), 46.

[32] Tyagi P., Vedeshwar A.G., Physica B, 304 (2001), 166.

[33] KonijnendiuK W., Stevels J., J. Non-Cryst. Solids, 20 (1976), 193.

[34] Fox H. W., Zisman W. A., J. Colloid Sci., 7 (1952), 109.

[35] Gobrecht H., SEeck S., Bergt H.-E., Märtens A., Kossmann K., Phys. Status Solidi, 34 (1969), 569. 